\title{
Green Filters: A Low Cost an Effective Way to Treating Waste Water
}

\author{
Mahipal Singh Sankhla ${ }^{1 *}$, Ramesh Kumar Pandey ${ }^{1}$, Kapil Parihar ${ }^{2}$, Rajeev Kumar ${ }^{3}$ \\ ${ }^{I}$ Research Scholar, Division of Forensic Science, SBAS, Galgotias University, Greater Noida, India \\ ${ }^{2}$ Student of M.Sc. Forensic Science, Division of Forensic Science, SBAS, Galgotias University, Greater Noida, \\ India \\ ${ }^{3}$ Associate Professor, Division of Forensic Science, SBAS, Galgotias University, Greater Noida, India
}

*Corresponding Author:Mahipal Singh Sankhla,Division of Forensic Science, SBAS, Galgotias University, Greater Noida, India, Email:mahipal4n6@gmail.com

\begin{abstract}
Today, discharge of toxic materials through Industries, e-waste, sewage, dyes, heavy metals, chemicals compounds and pesticides are found in water bodies like lakes, rivers and ground water takes developed a major difficult, which increases their contaminations levels significantly. These contaminants and toxic compounds are challenging to remove by outdated water treatment processes. A new technique had developed by non-toxic method using green filters to remove water contaminants. These techniques are cost effective and easily available or doesn't harm in our environment. This paper provides an in-depth review for green filters synthesized using Nanotechnology and their efficiency to remove contaminated for waste water.
\end{abstract}

Keywords:Toxic, Water, Green Filters, Contaminations, etc.

\section{INTRODUCTION}

Green filter are used for sustainable water remediation and treatment is a good analysis of recognized procedures for removing metals from polluted water [1]. Recent advances in the field of nanotechnology and larger applications of nanoparticles have led to learn about the unexploited resources that already exist in nature for development of new methods in synthesis of nanoparticles. Commonly, nanoparticles can be readily formed using physical and chemical methods [2].Nanoparticles (NPs) are defined as materials with a size between 1 and $100 \mathrm{~nm}$. Their Nano size provides them more surface areas than the corresponding bulk forms, advanced reactivity and a tunable nature of several properties. These special properties have encouraged the development of nanoscience and the application of NPs in wide range of fields like biomedicine, cosmetics, electronic, food, environmental examination and remediation or paints [3].

Several of the nanomaterial synthesis or making techniques of nanomaterials include the usage of dangerous elements, low material changes and high energy requirements. So, an increasing need to develop an environmentally friendly procedure for nanomaterials synthesis without using dangerous chemicals is gaining importance. Green filters techniques using also microorganisms or leaf extracts have developed as a simple and possible another to plant synthetic processes and physical procedures [4].

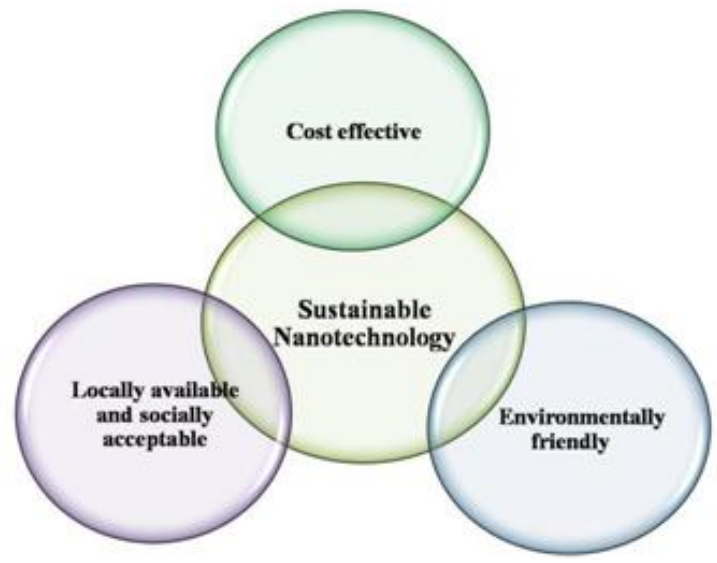

Figure1. Sustainable Green Filter Nanotechnology [5]

\section{REMOVAL METHOD FOR IRON NANOPARTICLES IN WASTE WATER}

Due to a number of restrictions of conventional procedures, review application has newly 
moved towards the improvement of clean and eco-friendly creation procedures. Nanomaterials can also be green filter, based on the use of leaf extracts which are responsible for the decrease of metallic complexes to appropriate nanomaterials. Green filter is not only ecologically friendly, but also low-cost. Because there is no requirement to use high temperatures, pressure, or supplementary energy contributions, it is easy to implement on a huge scales [5, 6]. Green filter to products Nano zero valent iron (nZVI) was first useful by Veru TEK and USEPA. Thesetechnique involved the preparation of a polyphenolic solution by warming leaf extracts (coffee, green tea, black tea, lemon, balm, sorghum, bran, grape etc.) in water to a temperature nearby to the boiling point. Extract ready in that technique is divided from the leaf filtrate and then mixed with a solution of $\mathrm{Fe} 2+$. The iron ions in the occurrence of polyphenols remained reduced to nZVI [7]. This green filters procedure for producing iron nanomaterials is considered as the most ecofriendly method and is still now commonly used.

Another different procedures e.g. hydro thermal production with leaf extracts, production with plant or leaf biodegradables -assisted production are further common in the production of iron oxide nanoparticles [8].The main disadvantages of using leaf extract for nanomaterials mixture is the devastation of leaf and plant amounts [9]. Extracts from several remains (skin, albedo, flesh) of such fruits as lemons, mandarins, limes, oranges or vine pomace $[6,10]$. Herb extracts decrease the metallic ions in a smaller period as associated to micro organisms. Contingent upon leaf category and application of phytochemicals reactions, nanomaterial remain complete within a limited time, although microorganism-based methods require a longer time. The main disadvantage of microorganism nanomaterial production is the required limitation of sterilized situations, which needs qualified supervisor, and increases the scalingup charge[8].Green filter ZVI has been positively used as a Fenton catalyst for oxidizing monochlorobenzene [11].The reducing agent are used dye such as malachitegreen [12] or bromothymol blue [7]. Former research's show the report of green nZVI it can be used to damage medicines (e.g. ibuprofen) in soils [10], $\mathrm{Cr}$ (VI) ions [13, 14], nitrate [15]. Treatment of swege waste water [20]. In spite of the various benefits of using this technique, green filter is still not generally believed. These consequences after lacking information of the reactivity, physicochemical belongings, and accumulation of the nanometrials formed [10]. The data presented in the writings shows that dependent of the kind of leaf isolation used for the manufacture of nZVI, we found nano particles with several dimensions and standards of particular surface area. Green filters can also be restricted by the lacking decrease of iron to nZVI by plant extracts [13], subsequent in of the construction of additional procedures of iron, e.g. iron oxides of hydroxides, in the progress of the development [12].

\section{Removal Method For Silver NANOPARTICLES IN WASTE WATER}

The newly collected leaf of cocaine (12 g) remained carefully washed with fresh tap water follow the procedure ultra-pure deionized water to remove the filth. The cleaned leaf sample was occupied in a $250 \mathrm{~mL}$ Erlenmeyer flask; $100 \mathrm{~mL}$ of miliQ was added and boiled at 80 1C for5min.The leaf extract was filtered through Watman's No.1 filter paper and the obtained filtrate was stored at $41 \mathrm{C}$ for further use for the green synthesis of AgNPs. In this study, the leaves extract acts as a reducing and protecting agent for the green synthesis of AgNPs. In a typical synthesis of AgNPs, $0.5 \mathrm{~mL}$ of I. coccinea leaves extract was added to $10 \mathrm{~mL}$ of $1 \mathrm{~m}$ MagNO3 aqueous solution and kept in a dark place at room temperature. After few minutes, the colorless reaction mixture changed to dark brown color which indicates the formation of AgNPs. The bio-reduced AgNPs were monitored by using a UV-vis spectrophotometer. The UV-vis spectra was recorded on a UV-vis spectrophotometer and the sample was measured in the wave- length region f200-800nm. The morphological studies of the synthesized AgNPs were viewed instrument. The greens synthesized AgNPs were centrifuged at $10,000 \mathrm{rpm}$ for $15 \mathrm{~min}$ to obtain the residue. The residual part of AgNPs was washed with deionized water and dried in a hot air oven at $601 \mathrm{C}$ for $24 \mathrm{~h}$. The crushed AgNPs were studied by a Bruker model D8 progressive concentrate X-ray diffractometer. The intensity data for the lyophilized nano silver powder were collected in the $2 y$ range $20-801$ and the scanning speed at $0.02 \mathrm{~min}$ per degree. The green filter of AgNPs was documented by JASCOFTIR spectrophotometer using $\mathrm{KBr}$ pellet in the range of $400-4000 \mathrm{~cm} \_1$ with the spectra resolution of $4 \mathrm{~cm} \_1$ [17]. 


\section{Removal Method For Cadmium IN WASTE WATER}

The new leaf was Ficus tree (FicusBenjamina). This leaf is from the Moraceae family and is one of the maximum rich flowering plant life in Australia and Asia. The leaf can also be create in the Conditions of Florida and Arizona in the United States and in the West Indies. Ficusbenjaminais a tree that in usual situations can spread 30m. FicusBenjamina was used as a biodegradable of $\mathrm{Cd}$ (II). The leaf were clean with tap water, de-ionized water drying in oven at $50 \mathrm{C}$ before cut onto minor particles. To make the extract of FicusBenjamina leaf, take $20 \mathrm{~g}$ of leaf in Erlenmeyer flask $(250 \mathrm{~mL})$ then add 100 $\mathrm{mL}$ of sterilized distilled water, boil the previous solution for $5 \mathrm{~min}(60 \mathrm{C})$. Later boiling for $5 \mathrm{~min}$ the mixture was cleaned and the filtrate will be stored at $4 \mathrm{C}$ until used as a decreasing and preservative resources for the preparation of nanomaterials production procedure. For production $\mathrm{Ag} 0$ nanomaterials procedure, take $2 \mathrm{ml}$ of FicusBenjamina leaf extract (FBLE) and add to $25 \mathrm{~mL}$ of AgNO3 (1 $\mathrm{Mm})$. The explanation modifications its pigment to brown. Finally, the solution enthused for 40 min to form the silver nanomaterials. This experimentation was accompanied at room temperature $(25 \mathrm{C})$. The presence of brown color shows the development of $\mathrm{Ag}$ nanomaterials. Color modifications to brown within 20 min shows that the AgNPs is made. The categorizations of the made $\mathrm{Ag}$ nanomaterials were studied. The illustrations remained occupied at different times and examined by UV- Vis spectrophotometer on UV- Vis measuring lead: Varian ICP - AES. FT-IR studies were completed to notice the development of nanomaterials of Ago. FT-IR ranges have remained taken for dried nanomaterials, done by a Fourier-transform infrared spectrophotometer by crushing the samples dust with potassium bromide for FTIR spectra tests. Scanning electron microscopy (SEM): A tinny picture of nanomaterials was designed on a copper slide protected with carbon, use impairing paper to eliminate the removal resolution and then dry the picture underneath the mercury spotlight for $5 \mathrm{~min}$. Before the picture was located in the container and presented hooked on the microscope [18].

\section{Removal Method For novel Nano- HYDROXYAPATITE IN WASTE WATER}

All the compounds used for the tests were analytical markfound from sigma Aldrich.
Moringaoleiferaleaf were collected and the leaf were wash away with Milli-Q water then cleaned with acetone to remove the surface impurities. After drying, they remained ground into fine dust by ball crushing and absorbed in 5 $\mathrm{ml}$ of conc. HNO3 and before put into microwave radiation for $2 \mathrm{~min}$ at $50 \mathrm{~W}$ to remove organic componds. Then, they were broadly wash away with Milli-Q water and dry in vacuum oven for $2 \mathrm{~h}$ at $150{ }^{\circ} \mathrm{C}$. $1 \mathrm{~g}$ of Moringaoleiferaleaf dust was then mixed with $0.1 \mathrm{M}$ of EDTA solution to method Ca-EDTA complex. Then, $0.06 \mathrm{M}$ of $\left(\mathrm{NH}_{4}\right) 2 \mathrm{HPO} 4$ solution was gradually supplementary with gained Ca-EDTA complex and sonicated for 30 $\min$. The $\mathrm{pH}$ of the response combination was adjusted to 10 by the adding of $\mathrm{NaOH}$ solution. Consequently, the arranged reaction combination was put in a microwave oven (A CEM Discover microwave synthesizer 2455 $\mathrm{MHz}, 300 \mathrm{~W}$ ) and irradiated with microwave $100 \mathrm{~W}$ for $5 \mathrm{~min}$. The white hurried found was washed and dried out in hot air oven at $150{ }^{\circ} \mathrm{C}$ for $3 \mathrm{~h}$. The chemical and phase composition of the nano-HAP was determined by Fourier transform infrared spectroscopy, X-ray beam photo electron spectroscopy and X-ray diffraction analysis. The structural and morphological structures of the as-synthesized nanoparticles were examined with a field production scanning electron microscope and transmission electron microscope [19].

\section{DISCUSSION}

This Review paper present green filters are used low-cost, safe and easily available for treatment for waste water contamination to purified water. The purpose of waste water treatment to drinking water for anthropological existence and value of human life\& aquatic life. The need green filters nanotechnology for maintainable water treatment, as populations continue to develop, and economies develop urban water, decontaminated drinking water through domestic water treatment device. There is a major changes in chemical configurations of herbal or leaf extract of same types when it collected from different parts of world and may lead to dissimilar consequences in different research laboratory. The determination is completed to highlight the several green Filters for the synthesis of nanoparticles such as polymers, amino acids, bacteria, fungi, herbal extracts and toxic compound to remove water and their response ways to approximately range. 


\section{CONCLUSION}

Green filter nanoparticles use for remove contamination of drinking water. Green filter nanotechnology developments, as defined in this review paper, deliver a solid basis on behalf of the structure of a change of biodegradables or functionalized nanomaterials that can work as structure blocks in the growth of fresh products that can be related in ecofriendly renewal areas. improving the significant parameters affecting the removal process, analytic concentration, $\mathrm{pH}$, type of disperser solvent, absorption time, ionic strength effect, type of desorption solvent and desorption time examined.The application of green filters nanomaterials in the remediation of the environment not only complete the attention of possible harmful elements, but also complete the charges of huge amount of remediation and the period of the procedure.

\section{REFERENCES}

[1] Anuradha Mishra and James H. Clark (Eds.), "Green materials for sustainable water remediation and treatment", Book review, DOI 10.1515/gps-2014-0025 Green Process Synth 2014; 3: 253, RSC Publishing, 2013, ISBN: 978-1-84973-621-3.

[2] A. Alqudami, S. Annapoorni, Plasmonics 2 (2007) 5-13.

[3] M. Shah, D. Fawcett, S. Sharma, S.K. Tripathy, G.E.J. Poinern, Green Synthesis of Metallic Nanoparticles via Biological Entities, Materials 8 (2015) 7278-7308.

[4] Huang, J., Li, Q., Sun, D., Lu, Y., Su, Y., Yang, X., Wang, H., Wang, Y., Shao, W., He, N., Hong, J. and Chen, C. "'Biosynthesis of silver and gold nanoparticles by novel sundried Cinnamomumcamphora leaf', Nanotech, 18, pp. 105104-105115 (2007).

[5] Sadia Saif et al; "Green Synthesis of Iron Nanoparticles and Their Environmental Applications and Implications", Nanomaterials 2016, 6, 209; doi: 10.3390/nano6110209, www.mdpi.com/journal/ nanomaterials.

[6] S. Machado, S.L. Pinto, J.P. Grosso, H.P.A. Nouws, J.T. Albergaria, C. Delerue-Matos, Green production of zero-valent iron nanoparticles using tree leaf extracts, Science of The Total Environment. 445-446 (2013) 18. doi:10.1016/j.scitotenv.2012.12.033.

[7] S. Machado, J.P. Grosso, H.P.A. Nouws, J.T. Albergaria, C. Delerue-Matos, Utilization of food industry wastes for the production of zerovalent iron nanoparticles, Science of The Total Environment. 496 (2014) 233-240. Doi: 10.1016/j.scitotenv.2014.07.058.

[8] G.E. Hoag, J.B. Collins, J.L. Holcomb, J.R. Hoag, M.N. Nadagouda, R.S. Varma,
Degradation of bromothymol blue by "greener" nano-scale zero-valent iron synthesized using tea polyphenols, J. Mater. Chem. 19 (2009) 8671-8677. Doi: 10.1039/B909148C.

[9] M. Herlekar, S. Barve, R. Kumar, PlantMediated Green Synthesis of Iron Nanoparticles, Journal of Nanoparticles. 2014 (2014) e140614. doi:10.1155/2014/140614.

[10] T. Wang, X. Jin, Z. Chen, M. Megharaj, R. Naidu, Green synthesis of $\mathrm{Fe}$ nanoparticles using eucalyptus leaf extracts for treatment of eutrophic wastewater, Science of The Total Environment. 466-467 (2014) 210-213. doi:10.1016/j.scitotenv.2013.07.022.

[11] S. Machado, W. Stawinski, P. Slonina, A.R. Pinto, J.P. Grosso, H.P.A. Nouws, et al., Application of green zero-valent iron nanoparticles to the remediation of soils contaminated with ibuprofen, Sci. Total Environ. 461-462 (2013) 323-329. doi:10.1016/j.scitotenv.2013.05.016.

[12] Y. Kuang, Q. Wang, Z. Chen, M. Megharaj, R. Naidu, Heterogeneous Fenton-like oxidation of monochlorobenzene using green synthesis of iron nanoparticles, Journal of Colloid and Interface Science. 410 (2013) 67-73. doi:10.1016/j.jcis.2013.08.020.

[13] L. Huang, X. Weng, Z. Chen, M. Megharaj, R. Naidu, Green synthesis of iron nanoparticles by various tea extracts: Comparative study of the reactivity, SpectrochimicaActa Part A: Molecular and Biomolecular Spectroscopy. 130 (2014) 295-301. doi:10.1016/j.saa.2014.04.037.

[14] C. Mystrioti, D. Sparis, N. Papasiopi, A. Xenidis, D. Dermatas, M. Chrysochoou, Assessment of Polyphenol Coated Nano Zero Valent Iron for Hexavalent Chromium Removal from Contaminated Waters, (2014).

[15] C. Mystrioti, T.D. Xanthopoulou, N. Papassiopi, A. Xenidis, Comparative evaluation of five plant extracts and juices for nanoiron synthesis and application for hexavalent chromium reduction, Science of The Total Environment. 539 (2016) 105-113. doi:10.1016/j.scitotenv.2015.08.091.

[16] T. Wang, J. Lin, Z. Chen, M. Megharaj, R. Naidu, Green synthesized iron nanoparticles by green tea and eucalyptus leaves extracts used for removal of nitrate in aqueous solution, Journal of Cleaner Production. 83 (2014) 413419. doi:10.1016/j.jclepro.2014.07.006.

[17] Karuppiah M, Rajmohan R, "Green synthesis of silver nanoparticles using Ixoracoccinea leaves extract", Materials Letters 97 (2013) 141-143, www.elsevier.com/locate/matlet.

[18] K.M. Al-Qahtani / Egyptian Journal of Aquatic Research 43 (2017) 269-274.

[19] DharmanGovindaraj, MariappanRajan/ Materials Today: Proceedings 3 (2016) 2394- 
2398, Recent Advances In Nano Science And Technology 2015 (RAINSAT2015).

[20] P. C. Nagajyoti, K. D. Lee, and T. V. M. Sreekanth, "Heavy metals, occurrence and toxicity for plants: a review," Environmental Chemistry Letters, vol. 8, no. 3, pp. 199-216, 2010.

[21] S. Machado, W. Stawinski, P. Slonina et al., "Application of ' green zero-valent iron nanoparticles to the remediation of soils contaminated with ibuprofen," Science of the Total Environment, pp. 461323-464629, 2013.

[22] M. N. Nadagouda, A. B. Castle, R. C. Murdock, S. M. Hussain, and R. S. Varma, "In vitro biocompatibility of nanoscale zerovalent iron particles (NZVI) synthesized using tea polyphenols," Green Chemistry, vol. 12, no. 1, pp. 114-122, 2010.

Citation: Mahipal Singh Sankhla, Ramesh Kumar Pandey, KapilParihar, Rajeev Kumar. Green Filters: A Low Cost an Effective Way to Treating Waste Water. ARC Journal of Forensic Science. 2018 3(1):13-17. http://dx.doi.org/10.20431/2456-0049.0301003

Copyright: () 2018 Authors. This is an open-access article distributed under the terms of the Creative Commons Attribution License, which permits unrestricted use, distribution, and reproduction in any medium, provided the original author and source are credited. 